\title{
IMPLEMENTASI ANIMASI 2D PADA IKLAN LAYANAN MASYARAKAT SEBAGAI SOSIALISASI PENYAKIT DBD
}

\author{
Ratih Suryani \\ Herlambang Saputra \\ Adi Sutrisman \\ Program Studi D-4 Teknologi Informatika Multimedia Digital \\ Jurusan Teknik Komputer, Politeknik Negeri Sriwijaya \\ Jalan Srijaya Negara Bukit Besar, Palembang \\ No. Hp.: 081929290029 \\ E-mail: ratihsuryani31@gmail.com, herlambang@polsri.ac.id, adisutrisman@polsri.ac.id
}

\begin{abstract}
ABSTRAK
Penyakit Demam Berdarah Dengue (DBD) merupakan salah satu penyakit menular dan berbahaya. Maka dari itu, tujuan dari penelitian tentang "Implementasi Animasi 2D pada Iklan Layanan Masyarakat sebagai Sosialisasi DBD" ini adalah untuk menyadarkan masyarakat Kota Palembang tentang upaya mencegah dan menanggulangi DBD. Dalam iklan layanan masyarakat ini, upaya yang akan disosialisasikan dikemas dengan cerita fiktif yang diperankan oleh tokoh karakter 2D sehingga menjadi lebih menarik untuk diketahui. Selain itu, juga dilakukan penelitian terhadap keberhasilan iklan layanan masyarakat ini melalui dua aspek, yaitu aspek daya tarik iklan yang dinilai oleh para ahli bidang animasi dan aspek kualitas pesan iklan yang dinilai oleh masyarakat. Pendekatan dalam penelitian ini adalah kuantitatif dengan jenis penelitian deskriptif. Metode yang digunakan dalam penelitian ini adalah metode survei dengan menggunakan teknik kuesioner. Responden dalam penelitian ini berjumlah 10 orang ahli dan 30 orang masyarakat, yang didapatkan dari penyebaran kuesioner online. Hasil dari penelitian ini diketahui bahwa sikap 10 orang responden ahli mengenai iklan layanan masyarakat ini sejumlah $85,6 \%$ berada di kategori "Sangat Baik" dan sikap 30 orang responden masyarakat umum sejumlah 92,8\% berada di kategori "Sangat Setuju".
\end{abstract}

Kata kunci: animasi, iklan layanan masyarakat, DBD

\begin{abstract}
The Implementation of 2D Animation in Public Service Announcements as the Socialization of DBD Diseases. Dengue Hemorrhagic Fever (DBD) is one of the contagious and dangerous diseases. Therefore, the aim of the research of "The Implementation of $2 D$ Animation in Public Service Announcements as the Socialization of DBD Diseases" is to raise the awareness of Palembang's citizens about the prevention and control of DBD. In this public service announcement, the efforts of prevention and control of DBD are packed in a fictional story characterized by $2 D$ animation characters to make it more interesting. In addition, the research is also to discover the success of this public service announcement through 2 aspects, the attractiveness of advertising approved by multimedia experts and the quality of advertising messages approved by citizens. The approach implemented in this research was quantitative with descriptive type. The method used in this research was a survey method using questionnaire technique. The respondents were 10 experts and 30 citizens, data were obtained from the survey of online questionnaire. The results of this study showed that 10 expert respondents in the public service announcement were in the "Very Good category" of 85,6\% and 30 citizens were in the "Strongly Agree category" of 92,8\%.
\end{abstract}

Keywords: animation, public service announcement, $D B D$ 


\section{PENDAHULUAN}

Media publikasi yang efektif digunakan pada era teknologi berkembang seperti saat ini adalah media yang memiliki kaitan erat dengan teknologi seperti gadget, televisi, dan komputer. Hal ini dilakukan karena media seperti gadget dan televisi sudah menjadi kebutuhan bagi masyarakat dan menjadi bagian dari kebiasaan hidup yang dilakukan. Iklan merupakan media publikasi yang efektif untuk digunakan saat ini karena iklan memiliki kaitan yang erat dengan teknologi. Iklan dibedakan menjadi iklan komersial dan iklan layanan masyarakat. Iklan layanan masyarakat merupakan iklan nonkomersial dengan maksud mengajak, mendidik, mengarahkan, atau menghimbau masyarakat sebagai warga negara maupun warga dunia (Syarif \& Al Ahdaf, 2017). Hal tersebut menunjukkan bahwa iklan dapat digunakan sebagai media untuk mempromosikan ataupun mensosialisasikan suatu informasi yang dapat menjadi pengingat bagi masyarakat (penontonnya).

Jenis iklan ini dapat disampaikan melalui berbagai jenis media, di antaranya adalah media cetak, media luar ruang, media digital, dan media lain. Media cetak contohnya adalah koran, majalah, dan poster. Media luar ruangan adalah media yang berukuran besar dipasang di tempat-tempat terbuka seperti di pinggir jalan, di pusat keramaian, atau tempattempat khusus lainnya seperti di dalam bus kota, gedung, dan pagar tembok. Media digital adalah media seperti televisi dan handphone serta media lain yang dimaksud merupakan bentuk lain dari promosi seperti pin, stiker, dan sablon kaos (Santosa, 2009). Namun, untuk menyampaikan informasi yang kompleks atau menyeluruh, penyampaian iklan layanan masyarakat yang disebar melalui media digital dalam bentuk video dapat menjadikan informasi yang disampaikan menjadi lebih efektif (Setiawan, 2014). Informasi yang akan disampaikan adalah mengenai cara mencegah dan menanggulangi penyakit Demam Berdarah Dengue (DBD). Menurut data yang dihimpun Kementerian Kesehatan Republik Indonesia (Dinas Kesehatan, 2019), sepanjang 2017 diketahui ada sekitar 59.000 kasus demam berdarah di seluruh Indonesia, dengan lebih dari 400 kasus di antaranya berakhir dengan kematian. Jika kejadian ini terus-menerus dibiarkan, akan berpengaruh pada kualitas generasi penerus untuk ke depannya.

Berdasarkan hal tersebut, informasi yang disampaikan dalam iklan layanan masyarakat ini harus menjadi lebih menarik untuk ditonton serta diperlukan visualisasi yang baik sehingga pesan yang disampaikan mudah dimengerti. Hal ini dapat diwujudkan dengan memaksimalkan sisi grafis (tampilan) serta kualitas audio agar dapat berkesinambungan antara visual dan penjelasan. Maka dari itu, penulis memilih untuk mengembangkan video iklan layanan masyarakat ini menjadi video iklan yang dipadukan dengan media animasi 2D (Sukiyasa \& Sukoco, 2013) sehingga memberikan kesan yang baru dengan visual grafis yang menarik untuk diketahui oleh semua kalangan masyarakat. Video iklan layanan masyarakat dalam bentuk animasi 2D ini tidak hanya memberikan informasi tentang cara mencegah penyakit DBD, namun juga dikemas dalam suatu cerita fiksi yang diperankan oleh karakter animasi yang akan membuat penjelasan dalam video iklan layanan masyarakat ini menjadi lebih mudah dipahami. 


\section{METODE PENELITIAN}

Proses pembuatan iklan layanan masyarakat ini dimulai dengan membuat proses perancangan, pembuatan, hingga analisis hasil pengujian. Perancangan dalam penelitian ini adalah berupa perancangan iklan layanan masyarakat dan perancangan kuesioner. Dari perancangan iklan layanan masyarakat dan perancangan kuesioner tersebut, dapat diketahui solusi dari permasalahan yang ada. Dalam perancangan iklan layanan masyarakat berbasis animasi 2D tentang penyakit DBD ini terdapat tiga tahapan, yaitu praproduksi, produksi, dan pascaproduksi. Selain itu, perancangan video animasi 2D iklan layanan masyarakat ini merujuk pada suatu metode pengembangan. Perancangan iklan ini menggunakan metode pengembangan multimedia Luther (Hadi Sutopo, 2003). Proses perancangan iklan layanan masyarakat ini akan dijelaskan pada gambar 1 .

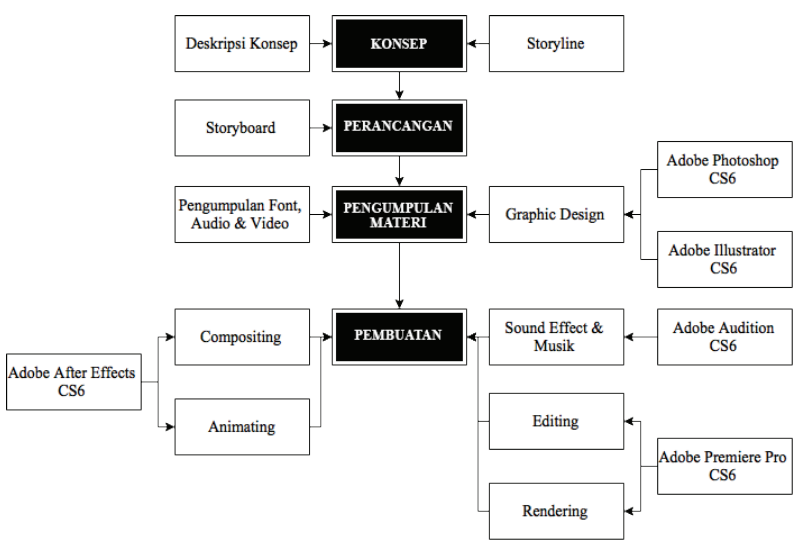

Gambar 1 Alur Pembuatan Video Iklan Layanan Masyarakat Animasi 2D Upaya Pencegahan DBD

Menurut Luther, pengembangan multimedia dapat dilakukan dengan metode Multimedia Development Life Cycle (MDLC), yaitu:

\section{Konsep (Concept)}

Merumuskan dasar-dasar dari proyek iklan animasi layanan masyarakat yang akan dibuat dan dikembangkan. Terutama pada tujuan dan jenis proyek yang akan dibuat.

\section{Desain (Design)}

Tahap pembuat atau pengembang proyek multimedia menjabarkan secara rinci apa yang akan dilakukan dan bagaimana proyek multimedia tersebut akan dibuat.

3. Pengumpulan Materi

Pengumpulan materi merupakan proses untuk pengumpulan segala sesuatu yang dibutuhkan dalam proyek.

4. Penyusunan dan Pembuatan

Waktunya proyek iklan animasi layanan masyarakat diproduksi. Materi-materi serta file-file multimedia yang sudah didapat kemudian dirangkai dan disusun sesuai desain.

Secara garis besar, proses produksi dibagi menjadi beberapa tahap sebagai berikut.

1. Praproduksi meliputi poin konsep dan perancangan. Yang dilakukan pada tahap ini adalah membuat konsep, cerita, dan skenario, karakter-karakter yang dikreasikan, color code, desain background, storyboard (Maulana, 2015).

2. Produksi meliputi poin pengumpulan materi (audio, video, graphic design, dan animating). Tahap ini dimulai dengan animate atau menganimasikan atau disingkat 'nganimasi' para karakternya setelah menjadi layout. Kemudian mengomposisikan dengan background ditambahkan dengan special effect, kemudian proses render animasi, sampai editing.

3. Pascaproduksi meliputi poin pembuatan (compositing, editing, rendering). Tahap ini dilakukan dengan menyatukan semua yang sudah dikerjakan dalam proses produksi, dilanjutkan dengan merapikan atau editing serta mixing audio dan musiknya sehingga menjadi sebuah tontonan yang siap tayang. 
Semua dilakukan secara bertahap dan sesuai dengan penjadwalan. Proses produksi harus diatur secara saksama agar tidak ada proses yang terlewatkan. Satu proses saja dilewatkan akan berdampak buruk dalam manajemen produksi yang mengakibatkan penambahan jadwal produksi.

\section{Deskripsi Konsep}

Berikut ini merupakan deskripsi dari konsep iklan layanan masyarakat berbasis animasi 2D yang akan penulis buat.

Tabel 1 Deskripsi Konsep

\begin{tabular}{ll}
\hline Judul & Mari Cegah Penyakit DBD! \\
\hline Jenis Iklan & Iklan Layanan Masyarakat \\
Target & Remaja dan Dewasa (14 tahun ke \\
Audiens & atas) \\
Ide Cerita & $\begin{array}{l}\text { DBD dapat membunuh harapan } \\
\text { anak bangsa }\end{array}$ \\
& Dokter menjelaskan kepada \\
& masyarakat tentang seorang \\
& anak yang bernama Liona. Dia \\
& adalah anak yang bersemangat \\
& dan ceria. Namun, semenjak \\
& menderita penyakit DBD, Ia \\
& berubah menjadi lesu dan tidak \\
& bersemangat. Melihat hal itu, \\
dokter pun bersama dengan \\
Ginopsis & gambiran tentang penyakit DBD \\
& dan cara mencegahnya. Dengan \\
demikian, penderita DBD tidak \\
bertambah banyak dan Liona \\
beserta keluarganya dapat \\
menjauhkan diri dari hal-hal yang \\
menyebabkan DBD. \\
Pahami dan terapkan pencegahan \\
dan penanggulangan DBD \\
agar hidup menjadi sehat dan \\
bersemangat.
\end{tabular}

\section{Pengumpulan Materi}

Pengumpulan materi merupakan proses untuk pengumpulan segala sesuatu yang dibutuhkan dalam proyek. Mengenai materi yang akan disampaikan, kemudian file-file multimedia seperti audio, video, dan gambar yang akan dimasukkan dalam penyajian proyek multimedia tersebut (Hadi Sutopo, 2003). Pengumpulan materi berupa file gambar graphic design akan digunakan untuk tahap animating; logo; yaitu logo Politeknik Negeri Sriwijaya, logo Program Studi Teknologi Informatika Multimedia Digital; file font; serta file-file audio berupa sound effect dan musik instrumen.

1. Desain Asset 2D

Pembuatan asset dilakukan dengan menggunakan software desain digital. Desain asset yang dibuat meliputi seluruh asset yang telah dirancang pada storyboard. Berikut ini rincian asset yang didesain:

a. Desain Karakter Manusia yang meliputi Karakter Liona, Ayah, dan Ibu dan Desain Karakter Hewan yang meliputi Nyamuk dan Burung.

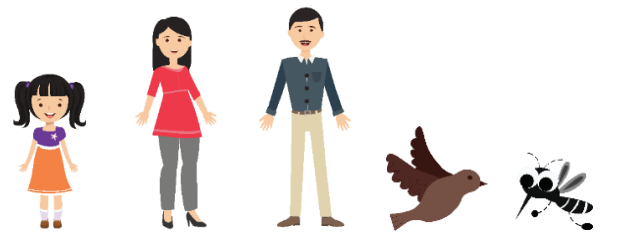

Gambar 2 Desain Karakter Manusia dan Hewan dalam Iklan Layanan Masyarakat Animasi 2D Upaya Pencegahan DBD

b. Desain Environtment Exterior Perumahan yang merupakan layout yang tersusun dari asset 2D seperti Rumah-rumah, Pohonpohon, Rumput, Awan, Mobil Ambulans, Jalan, dan Rumah Sakit.

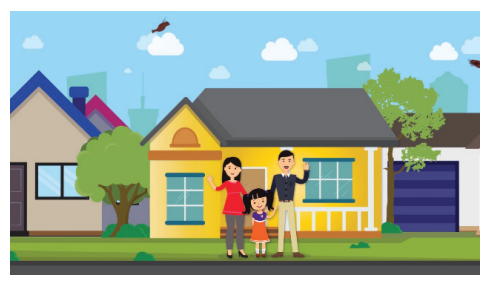

Gambar 3 Desain Environtment Exterior Perumahan 
c. Desain Environtment Interior Rumah Liona, yaitu ruang tengah yang merupakan layout yang tersusun atas asset 2D seperti Pintu, Jendela, dan Rak Vas Bunga, dan Toilet yang tersusun atas asset 2D bathtub, ember, tangki, dan gorden.

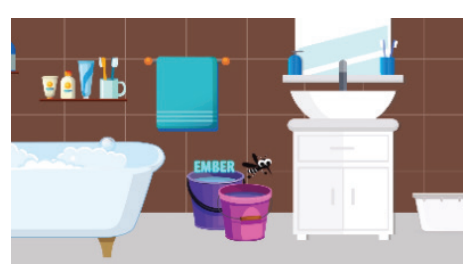

Gambar 4 Desain Environtment Interior Ruang Tengah dan Toilet Rumah Liona

d. Desain Environtment Interior Rumah Sakit yang terdiri dari pintu, tempat tidur pasien, dan termometer.

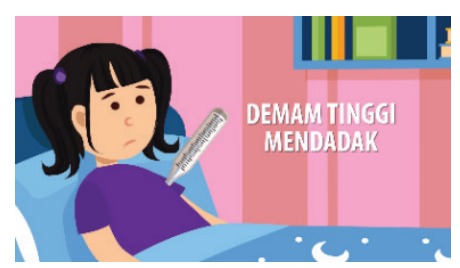

Gambar 5 Desain Environtment Interior Rumah Sakit

\section{Rekaman Suara}

Rekaman suara digunakan sebagai narasi (voice over) dalam video animasi 2D iklan layanan masyarakat tentang pencegahan dan penanggulangan penyakit DBD. Pada proses rekaman suara untuk narasi (voice over), penulis menggunakan aplikasi voice recorder yang terdapat pada smartphone berjenis Apple Iphone 4S. Format file recorder pada aplikasi ini adalah *m4a dengan audio bitrate $64 \mathrm{kbps}$.

\section{Pengumpulan Materi Tambahan}

Selain pengumpulan file desain asset 2D dan rekaman suara narasi, penulis juga menggunakan materi tambahan lain berupa file font, gambar, dan musik. Beberapa dari file tersebut penulis dapatkan dengan cara mengunduh dari beberapa situs internet.
Berikut merupakan beberapa contoh materi yang digunakan dalam pembuatan video iklan ini.

Tabel 2 Beberapa Contoh Materi Audio

\begin{tabular}{rlcc}
\hline No. & Nama File & $\begin{array}{c}\text { Format } \\
\text { File }\end{array}$ & Keterangan \\
\hline 1. & $\begin{array}{l}\text { Energetic } \\
\text { Upbeat Pop } \\
\text { Summer }\end{array}$ & $\mathrm{mp} 4$ & Backsound \\
2. & $\begin{array}{l}\text { Happy } \\
\text { Moments }\end{array}$ & $\mathrm{mp} 4$ & Backsound \\
\hline 3. & VO DBD & $\mathrm{m} 4 \mathrm{a}$ & Narasi \\
\hline
\end{tabular}

\section{Konsep Teknik Animating}

Tahap animating dibuat dengan menggunakan software Animasi Digital dan menganimasikan 12 scene sesuai dengan storyline dan storyboard yang telah dibuat. Beberapa teknik yang digunakan pada konsep animating video iklan layanan masyarakat ini adalah:

1. Rigging Karakter Manusia (Puppet tool) Untuk dapat menggerakkan anggota tubuh dari karakter manusia serta hewan dalam scene 1 dan 2 seperti menggerakkan tangan, mata, kaki, rambut, dan kepala, penulis menggunakan teknik rigging dengan puppet tool. Teknik ini dilakukan dengan memberikan tulang (rig) menggunakan puppet di bagian tubuh karakter seperti kepala, tangan, dan kaki serta susunannya meniru rangka tulang persendian manusia dan hewan tersebut. Selain itu, rig juga diberikan di bagian-bagian pada wajah, seperti alis dan mata. Karena membuat ekspresi wajah yang ekspresif dan realistik tidak hanya meliputi pergerakan utama tulang wajah, namun juga meliputi variasi gerak alis, gerak hidung, dan perubahan dahi. Pergerakan-pergerakan tersebut ikut menentukan tingkat ekspresif dari sebuah ekspresi wajah (Gunanto, 2018). 


\section{Basic Animation}

Teknik ini merupakan teknik dasar dari animasi pada After Effects. Terdapat animasi position (posisi), rotation (rotasi), scale (skala), dan opacity (transparansi). Teknik ini digunakan hampir dalam setiap scene.

3. Masking

Maskingdigunakanuntukmenyembunyikan sebagian atau semua bagian dari sebuah objek menggunakan bentuk dari objek lain. Teknik ini digunakan dalam scene 4.

4. Text Animation

Text Animation merupakan animasi khusus dalam teks sehingga penulis dapat menganimasikan per huruf, per kata, ataupun per baris kalimat. Teknik ini digunakan hampir dalam setiap scene.

\section{Efek CC Rainfall}

Efek Rainfall digunakan penulis untuk memberikan suasana hujan dalam salah satu scene yang ada di video iklan layanan masyarakat. Penggunaan efek cc rainfall dapat dilihat dalam scene 4 .

\section{Konsep Editing}

Tahap editing adalah tahap footage video animasi hasil render dari file proyek di software Animasi Digital, digabungkan dan disusun menjadi satu kesatuan sesuai dengan alur cerita (script) dan storyline yang telah dibuat. Editing ini menggunakan software editor video. Proses editing dilakukan dengan menggunakan beberapa teknik yang mendukung penyusunan video menjadi lebih rapi dan menarik. Berikut merupakan teknik yang dipakai dalam proses editing.

\section{Add Cut Point}

Teknik Add Cut Point dilakukan dalam scene yang masih memiliki durasi yang kurang pas, dengan cara memotong sebagian dari scene tersebut agar potongan bisa diubah kecepatannya tanpa mengubah kecepatan keseluruhan dari scene tersebut. Beberapa scene yang diberikan Add Cut Point adalah scene 7 dan 3.

\section{Speed/Duration}

Teknik ini digunakan dalam scene 10, digunakan untuk mempercepat atau memperlambat durasi dari sebuah scene. Penulis menggunakannya untuk scene yang masih memiliki durasi yang kurang pas.

3. Import Sound Effect dan Musik

Tahap ini penulis memasukkan file audio yang telah dikumpulkan pada tahap sebelumnya ke dalam sequence yang sudah dibuat pada Software Editing Video.

4. Dip to Black

Teknik dip to black digunakan dalam transisi scene 2 ke scene 3 dan scene akhir. Teknik ini digunakan untuk membuat video bertransisi menjadi warna hitam (gelap). Hal ini berguna untuk memperjelas beberapa bagian dalam iklan seperti pada saat transisi dari scene pembuka menuju ke penjelasa serta transisi dari scene akhir menuju ke penutup.

5. Audio Gain

Teknik ini merupakan teknik untuk mengatur tinggi rendahnya suara sesuai dengan satuan decibel (dB) yang diinginkan. Teknik ini digunakan pada semua audio agar tingkat kekerasan suara hampir sama rata.

6. Constan Gain, Constant Power dan

\section{Exponential Fade}

Teknik ini digunakan untuk membuat audio agar bersuara pelan pada awal untuk Constan Gain dan bersuara pelan di akhir 
degan menggunakan Exponetial Fade serta memperhalus transisi suara dengan menggunakan Constant Power.

\section{Perancangan Kuesioner}

Penelitian ini mengambil sampel sebanyak 10 orang responden ahli (alfa) dan 30 orang responden dari masyarakat umum (beta) dengan menggunakan teknik angket kuesioner. Variabel yang digunakan adalah kualitas pesan iklan dan daya tarik iklan yang dilihat dari segi tampilan. Respons pengujian ditujukan untuk memberikan kesimpulan bahwa hasil video animasi 2D iklan layanan masyarakat sesuai dengan tujuan pembuatan.

Selain mengajukan pertanyaan tentang data penilaian video iklan dari segi konten informasi dan data dari segi tampilan, kuesioner juga dilakukan untuk mengumpulkan biodata responden. Data yang diambil dalam biodata responden adalah nama, umur, jenis kelamin, dan tingkat pendidikan.

\section{Kuesioner Alfa (Ahli)}

Kuesioner alfa adalah kuesioner yang diberikan kepada para ahli di bidang multimedia dan animasi. Tujuan dari kuesioner alfa adalah untuk mengetahui kelayakan dari video animasi 2D iklan layanan masyarakat yang telah dibuat untuk ditampilkan. Penilaian yang dilakukan dalam kuesioner ini adalah dari segi tampilan video iklan. Terdapat lima jenis pilihan jawaban yang dapat dipilih responden, yaitu SK (Sangat Kurang), K (Kurang), C (Cukup), B (Baik), dan SB (Sangat Baik). Selain itu, pertanyaan yang diajukan dalam mewakili kriteria dari segi tampilan terdapat empat pertanyaan. Pertanyaan tersebut seperti yang terdapat dalam tabel 3.
Tabel 3 Pertanyaan Kuesioner Alfa tentang Daya Tarik Iklan

\begin{tabular}{|c|c|c|c|c|c|c|}
\hline No. & Pertanyaan & \multicolumn{5}{|c|}{ Pilihan Jawaban } \\
\hline & $\begin{array}{c}\text { dari segi } \\
\text { gambar/ } \\
\text { grafis? }\end{array}$ & SKB & $\mathrm{KB}$ & $\mathrm{C}$ & B & SB \\
\hline 2 & $\begin{array}{c}\text { Apakah iklan } \\
\text { ini menarik } \\
\text { dari segi } \\
\text { warna? }\end{array}$ & SKB & $\mathrm{KB}$ & $\mathrm{C}$ & B & SB \\
\hline 3 & $\begin{array}{c}\text { Apakah iklan } \\
\text { ini menarik } \\
\text { dari segi } \\
\text { audio? }\end{array}$ & SKB & $\mathrm{KB}$ & $\mathrm{C}$ & B & SB \\
\hline
\end{tabular}

2. Kuesioner Beta

Kuesioner beta adalah kuesioner yang diberikan kepada masyarakat umum yang berumur $\geq 14$ tahun. Tujuan dari kuesioner beta adalah untuk mengetahui kualitas dari pesan yang disampaikan dalam video animasi 2D iklan layanan masyarakat serta kemenarikan video iklan dari segi tampilan. Kualitas pesan digunakan untuk mengetahui apakah informasi yang disampaikan dapat dipahami dengan baik atau tidak serta apakah dapat membuat masyarakat menjadi lebih tertarik untuk mengetahuinya atau tidak. Selain itu, tujuan pelibatan penonton adalah untuk mengamati bagaimana proses kognitif itu berlangsung melalui pengamatan penonton terhadap unsur filmis dalam hal ini iklan layanan masyarakat (Hasan, Simatupang, \& Saputro, 2018). Penilaian yang dilakukan dalam kuesioner ini adalah dari segi Kualitas Pesan Iklan dan dari segi Tampilan Iklan. Terdapat lima pilihan jawaban yang dapat dipilih responden, yaitu STS (Sangat Tidak Setuju), TS (Tidak Setuju), R (Ragu), S (Setuju), dan SS (Sangat Setuju). Pertanyaan untuk masing-masing kriteria dapat dilihat dalam tabel 4. 
Tabel 4 Pertanyaan Kuesioner Beta tentang Kualitas Pesan Iklan

\begin{tabular}{|c|c|c|c|c|c|c|}
\hline \multirow{2}{*}{ No. } & \multirow{2}{*}{$\begin{array}{l}\text { Pertanyaan } \\
\text { Apakah Anda setuju, setelah melihat video iklan layanan masyarakat } \\
\text { ini Anda mengetahui tentang apa itu penyakit DBD? }\end{array}$} & \multicolumn{5}{|c|}{ Pilihan Jawaban } \\
\hline & & SS & $\mathrm{S}$ & $\mathrm{R}$ & TS & STS \\
\hline 2. & $\begin{array}{l}\text { Apakah Anda setuju, setelah melihat video iklan layanan masyarakat } \\
\text { ini Anda mengetahui tentang penyebab dari penyakit DBD? }\end{array}$ & SS & $\mathrm{S}$ & $\mathrm{R}$ & TS & STS \\
\hline 3. & $\begin{array}{l}\text { Apakah Anda setuju, setelah melihat video iklan layanan masyarakat } \\
\text { ini Anda mengetahui tentang cara mencegah penyakit DBD? }\end{array}$ & SS & $\mathrm{S}$ & $\mathrm{R}$ & TS & STS \\
\hline 4. & $\begin{array}{l}\text { Apakah Anda setuju, setelah melihat video iklan layanan masyarakat } \\
\text { ini Anda mengetahui tanda-tanda dari penyakit DBD? }\end{array}$ & SS & S & $\mathrm{R}$ & TS & STS \\
\hline 5. & $\begin{array}{l}\text { Apakah Anda setuju, setelah melihat video iklan layanan masyarakat } \\
\text { ini Anda mengetahui tentang cara menanggulangi penyakit DBD? }\end{array}$ & SS & $\mathrm{S}$ & $\mathrm{R}$ & TS & STS \\
\hline 6. & $\begin{array}{l}\text { Apakah Anda setuju setelah menonton Iklan Layanan masyarakat ini, } \\
\text { Anda akan menerapkan upaya-upaya pencegahan penyakit DBD? }\end{array}$ & SS & $\mathrm{S}$ & $\mathrm{R}$ & TS & STS \\
\hline 7. & $\begin{array}{l}\text { Apakah Anda setuju setelah menonton Iklan Layanan masyarakat ini, } \\
\text { Anda akan menerapkan upaya-upaya pencegahan penyakit DBD? }\end{array}$ & SS & $\mathrm{S}$ & $\mathrm{R}$ & $\mathrm{TS}$ & STS \\
\hline
\end{tabular}

\section{Tes Kinerja Sistem}

Tes kinerja sistem dilakukan dengan cara pengujian terhadap responden ahli (alfa) dan pengujian terhadap responden masyarakat umum. Pengujian ini dilakukan dengan cara yang sama, yang membedakan adalah objek penelitian. Pada pengujian terhadap responden, dengan sosialisasi secara langsung kepada masyarakat terhadap iklan layanan masyarakat tentang demam Berdarah Dengue yang telah dibuat. Setelah dilakukan sosialisasi, tahapan yang akan dilakukan adalah mengolah data dan menganalisis data hasil sosialisasi tersebut untuk mengetahui tingkat keberhasilan iklan layanan masyarakat yang dibuat.

Respons pengujian ditujukan untuk memberikan kesimpulan bahwa video ini layak atau tidak untuk ditonton dan dipublikasikan. Pengujian dilakukan dengan cara menyebarkan kuesioner menggunakan kuesioner online (google form). Analisis data yang akan dilakukan menggunakan metode perhitungan dengan skala likert (Sugiyono, 2012). Terdapat lima pilihan jawaban pada kuesioner, nilai setiap item yang merupakan hasil dari pilihan responden akan dikalkulasikan dengan bobot setiap item pilihan.

1. Penentuan Skor Jawaban

Hal pertama yang harus dilakukan adalah menentukan skor dari tiap jawaban yang akan diberikan. Skor jawaban atau disebut juga nilai skala telah ditentukan sesuai dengan aturan metode skala likert (Sugiyono, 2012). Tabel 5 merupakan pembagian skor nilai untuk setiap poin jawaban sesuai dengan peraturan skala likert.

\begin{tabular}{lc}
\multicolumn{2}{c}{ Tabel 5 Nilai Skala $\left(N_{S}\right)$} \\
\hline \multicolumn{1}{c}{ Item Jawaban $(\mathrm{I})$} & Nilai Skala $\left(N_{S}\right)$ \\
\hline SB (Sangat Baik) & 5 \\
B (Baik) & 4 \\
C (Cukup) & 3 \\
KB (Kurang Baik) & 2 \\
\hline SKB (Sangat Kurang Baik) & 1 \\
\hline
\end{tabular}

2. Skor Ideal (Kriterium)

Skor ideal digunakan untuk menentukan rating scale dan jumlah seluruh jawaban. Untuk menghitung jumlah skor ideal (kriterium) dari seluruh item digunakan rumus berikut, yaitu: 


$$
\mathrm{K}=N_{S} \times \mathrm{J}
$$

Keterangan:

$$
\begin{array}{ll}
\mathrm{K} & : \text { Skor Kriterium } \\
N_{S} & : \text { Nilai Skala } \\
\mathrm{J} & : \text { Total Responden }
\end{array}
$$

Seandainya skor tertinggi adalah 5 dan jumlah responden 20, maka menjadi:

Tabel 6 Skor Kriterium (Ideal)

\begin{tabular}{cc}
\hline Skor Kriterium $(\mathrm{K})$ & Skala \\
\hline $5 \times 20=100$ & SB \\
$4 \times 20=80$ & B \\
$3 \times 20=60$ & $\mathrm{C}$ \\
$2 \times 20=40$ & KB \\
\hline $1 \times 20=20$ & SKB \\
\hline
\end{tabular}

Selanjutnya semua jawaban responden dijumlahkan dan dimasukkan ke dalam rating scale dan ditentukan daerah jawabannya.

\section{Rating Scale}

Selanjutnya, menentukan interval (I) yang akan digunakan sebagai interval antarskala. Lihat rumus berikut ini.

$$
\begin{aligned}
& I=\frac{100 \%}{\text { Jumlah Skor Likert }} \\
& I=\frac{100 \%}{5} \\
& I=20 \%
\end{aligned}
$$

Keterangan $: \mathrm{I}=$ Interval

Skor yang telah diperoleh kemudian dimasukkan ke dalam rating scale berikut ini.

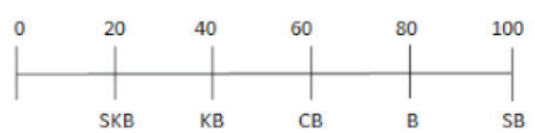

Gambar 2 Rating Scale

Rating scale berfungi untuk mengetahui hasil data angket (kuesioner) secara umum dan keseluruhan yang didapat dari penilaian angket (kuesioner). Dengan ketentuan sebagai berikut.

Tabel 7 Rating Scale

\begin{tabular}{cc}
\hline Nilai Jawaban & Skala \\
\hline Angka $80 \%-100 \%$ & SB \\
Angka $60 \%-79,99 \%$ & B \\
Angka $40 \%-59,99 \%$ & C \\
Angka 20\%-39,99\% & KB \\
\hline Angka 0\%-19,99\% & SKB \\
\hline
\end{tabular}

4. Persentase Persetujuan

Presentase persetujuan disebut juga $R_{i}$ atau Rumus Index. Untuk mengetahui jumlah jawaban dari para responden melalui persentase, yaitu digunakan rumus sebagai berikut.

$$
R_{i}=\frac{\text { Total Skor }}{\mathrm{Y}} \times 100 \%
$$

Keterangan:

$R_{i} \quad$ : Rumus Index

Y : Skor Tertinggi

100 : Bilangan tetap

Namun, sebelum menentukan nilai dari Total Skor dan $\mathrm{Y}$, langkah pertama yang harus dilakukan adalah menentukan nilai jawaban dari 
masing-masing item (I) dengan cara berikut ini:

$$
I_{n}=x_{n} \times B
$$

\section{Keterangan:}

$I_{n}:$ Nilai dari jawaban setiap pilihan

$x_{n}$ : Jumlah responden yang memilih pilihan jawaban

$B$ : Bobot nilai skor likert dalam pilihan jawaban

Langkah kedua tentukan nilai total dari jawaban semua item (Total Skor) dengan cara berikut ini. Total Skor $=I_{s k}+I_{k}+I_{c}+I_{b}+I_{s b}$

\section{Keterangan:}

$I_{s k}:$ Jumlah responden yang memilih jawaban Sangat Kurang

$I_{k}$ : Jumlah responden yang memilih jawaban Kurang

$I_{c}$ : Jumlah responden yang memilih jawaban Cukup

$I_{h}$ : Jumlah responden yang memilih jawaban Baik

$I_{s h}:$ Jumlah responden yang memilih jawaban Sangat Baik

Langkah selanjutnya adalah menentukan jumlah skor tertinggi $(\sqrt{\mathrm{Y}})$ dengan cara berikut.

$\mathrm{Y}=\mathrm{T}_{t} \times \mathrm{J}$

Keterangan:

Y : Jumlah skor tertinggi

$\mathrm{T}_{t}$ : Skor tertinggi likert (5)

$\mathrm{J}$ : Jumlah semua responden

\section{HASIL DAN PEMBAHASAN}

\section{Hasil}

\section{Realisasi Iklan Layanan Masyarakat}

Setelah selesai melakukan serangkaian tahap perancangan, akan didapat hasil video dengan format *MP4. Video ini dapat diputar hampir di semua perangkat lunak pemutar video ternama saat ini. Penulis mencoba untuk memutarnya di Windows Media Player. Berikut merupakan hasil tampilan animasi Iklan Layanan Masyarakat tentang Upaya Pencegahan Penyakit DBD ini dari beberapa scene.

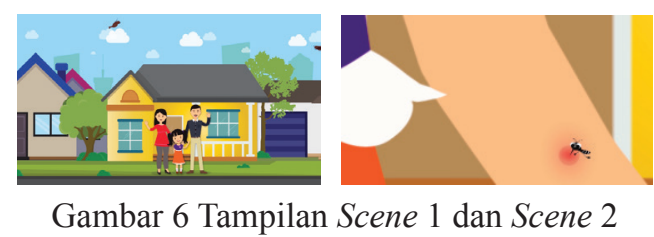

Video animasi 2D iklan layanan masyarakat yang dibuat oleh penulis berdurasi 6 menit 58 detik menggunakan format jenis codec H.264 dengan output berupa file *MP4, yang bisa diputar oleh berbagai perangkat lunak pemutar video. Video ini telah siap untuk didistribusikan dengan cara diberikan kepada siswa SMA serta masyarakat umum sebagai objek penelitian dari iklan layanan masyarakat tentang upaya pencegahan penyakit DBD.

\section{Data Hasil Pengujian dan Analisis}

Setelah dilakukan pengujian terhadap responden, diperoleh data hasil pengujian terhadap iklan layanan masyarakat animasi 2D tentang upaya pencegahan dan penanggulangan penyakit DBD. Data hasil pengujian oleh Alfa (Ahli) dapat dilihat dalam tabel 8, dan data hasil pengujian kuesioner Beta (Masyarakat) dapat dilihat dalam tabel 9. 
Tabel 8 Data Persentase Hasil Kuesioner Alfa (Ahli)

\begin{tabular}{clccccc}
\hline No. & \multicolumn{1}{c}{ Pertanyaan } & SB & B & C & KB & SKB \\
\hline 1. & Apakah iklan ini menarik dari segi gambar/grafis? & 8 & 1 & 1 & 0 & 0 \\
2. & Apakah iklan ini menarik dari segi warna? & 2 & 7 & 1 & 0 & 0 \\
3. & Apakah iklan ini menarik dari segi tipografi (teks)? & 3 & 3 & 4 & 0 & 0 \\
4. & Apakah iklan ini menarik dari segi animasi? & 5 & 5 & 0 & 0 & 0 \\
\hline 5. & Apakah iklan ini menarik dari segi audio? & 3 & 6 & 1 & 0 & 0 \\
\hline
\end{tabular}

Berdasarkan data yang didapatkan dari hasil penyebaran kuesioner, dilakukan analisis data sesuai dengan cara yang dilakukan pada tes kinerja sistem. Dari hasil perhitungan nilai dalam pengujian alfa, rata-rata pengujian responden alfa 85,6\% dan berdasarkan kriteria indeks persentase yang telah ditentukan berada di kategori "Sangat Baik".

Tabel 9 Data Persentase Hasil Kuesioner Beta (Masyarakat)

\begin{tabular}{|c|c|c|c|c|c|c|}
\hline No. & Pertanyaan & SS & S & $\mathrm{R}$ & $\mathrm{TS}$ & STS \\
\hline 1. & $\begin{array}{l}\text { Apakah Anda setuju, setelah melihat video iklan layanan masyarakat } \\
\text { ini Anda mengetahui tentang apa itu penyakit DBD? }\end{array}$ & 23 & 7 & 0 & 0 & 0 \\
\hline 2. & $\begin{array}{l}\text { Apakah Anda setuju, setelah melihat video iklan layanan masyarakat } \\
\text { ini Anda mengetahui tentang penyebab dari penyakit DBD? }\end{array}$ & 20 & 10 & 0 & 0 & 0 \\
\hline 3. & $\begin{array}{l}\text { Apakah Anda setuju, setelah melihat video iklan layanan masyarakat } \\
\text { ini Anda mengetahui tentang cara mencegah penyakit DBD? }\end{array}$ & 17 & 13 & 0 & 0 & 0 \\
\hline 4. & $\begin{array}{l}\text { Apakah Anda setuju, setelah melihat video iklan layanan masyarakat } \\
\text { ini Anda mengetahui tanda-tanda dari penyakit DBD? }\end{array}$ & 18 & 12 & 0 & 0 & 0 \\
\hline 5. & $\begin{array}{l}\text { Apakah Anda setuju, setelah melihat video iklan layanan masyarakat } \\
\text { ini Anda mengetahui tentang cara menanggulangi penyakit DBD? }\end{array}$ & 20 & 10 & 0 & 0 & 0 \\
\hline 6. & $\begin{array}{l}\text { Apakah penyampaian informasi dengan pendekatan animasi seperti ini } \\
\text { mudah Anda pahami? }\end{array}$ & 19 & 11 & 0 & 0 & 0 \\
\hline 7. & $\begin{array}{l}\text { Apakah Anda setuju setelah menonton iklan layanan masyarakat ini, } \\
\text { Anda akan menerapkan upaya-upaya pencegahan penyakit DBD? }\end{array}$ & 18 & 11 & 1 & 0 & 0 \\
\hline
\end{tabular}

Berdasarkan data yang didapatkan dari hasil penyebaran kuesioner, dilakukan analisis data sesuai dengan cara yang dilakukan pada tes kinerja sistem. Dari hasil perhitungan nilai dalam pengujian beta, rata-rata pengujian responden beta $92,8 \%$ dan berdasarkan kriteria indeks persentase yang telah ditentukan berada di kategori "Sangat Setuju". 


\section{Pembahasan}

Setelah semua proses pada tahap perancangan dilakukan, dihasilkan suatu produk berupa video animasi 2D iklan layanan masyarakat tentang upaya pencegahan dan penanggulangan penyakit DBD dengan format berupa file *MP4. Video iklan ini berdurasi 6 menit 58 detik dan bisa diputar oleh berbagai perangkat lunak pemutar video. Selain itu, video iklan ini juga dapat dilihat pada sosial media, yaitu Youtube.

Pada tahap pengujian, setelah didapatkan hasil analisis data dan analisis pengujian dari responden alfa dan beta, dapat diketahui kelayakan dari video animasi 2D iklan layanan masyarakat tentang upaya pencegahan dan penanggulangan penyakit DBD ini untuk dapat ditampilkan kepada masyarakat.

Berdasarkan hasil dari analisis data dan pengujian dari responden alfa, dapat disimpulkan bahwa responden alfa merupakan orang memiliki kompetensi sebagai ahli dalam mengisi kuesioner dan hal ini dilihat dari profesi, jenis kelamin, tingkat pendidikan, dan jurusan pendidikan dari responden. Selain itu, hasil pengujian menunjukkan bahwa indeks persentase tingkat keberhasilan yang didapatkan oleh iklan ini sebesar 85,6\% dan berada di kategori "Sangat Baik". Dengan demikian, video iklan ini layak secara penampilan untuk dipublikasikan kepada masyarakat dari segi penilaian responden alfa (ahli).

Berdasarkan hasil analisis data dan pengujian dari responden beta, dapat diketahui bahwa dominasi responden beta memiliki jenjang pendidikan D4/S1 dan hasil pengujian terhadap iklan menunjukkan bahwa iklan ini mendapatkan skor indeks persentase keberhasilan sebesar 92,8\% dan berada di kategori "Sangat Setuju". Dengan demikian, video ini memberikan informasi yang bisa dipahami oleh masyarakat.

Dari kedua hasil tersebut, dapat diketahui bahwa video animasi 2D iklan layanan masyarakat tentang upaya pencegahan dan penanggulangan penyakit DBD ini layak untuk dipublikasikan serta dapat diterima oleh masyarakat. Hal tersebut dibuktikan dari hasil survei yang menunjukkan bahwa iklan ini memberikan informasi yang mudah dipahami sehingga dapat dijadikan sebagai media untuk mensosialisasikan pencegahan dan penanggulangan DBD secara lebih efektif.

\section{SIMPULAN}

Berdasarkan perancangan dan realisasi iklan layanan masyarakat berbasis animasi 2D yang telah dikerjakan, dapat diambil beberapa kesimpulan, yaitu pembuatan iklan layanan masyarakat ini menggunakan animasi 2D. Selanjutnya animasi 2D tersebut disusun melalui proses editing yang menarik sehingga informasi yang ingin disampaikan mudah untuk dicerna masyarakat.

Berdasarkan hasil uji kuesioner terhadap responden, dapat disimpulkan bahwa responden setuju bahwa video iklan ini layak secara penampilan untuk dipublikasikan kepada masyarakat dari segi penilaian responden alfa (ahli) dengan indeks persentase tingkat keberhasilan yang didapatkan oleh iklan ini sebesar $85,6 \%$ dan berada di kategori "Sangat Baik”. Selain itu, video ini memberikan informasi yang bisa dipahami oleh masyarakat dilihat dari indeks persentase keberhasilan sebesar 92,8\% dan berada di kategori "Sangat Setuju". 


\section{KEPUSTAKAAN}

Dinas Kesehatan. (2019). Pencegahan dan Pengendalian Penyakit Demam Berdarah Dengue di Kota Palembang. Palembang: Dinas Kesehatan.

Gunanto, S. G. (2018). Evaluasi Sintesis Ekspresi Wajah Realistik pada Sistem Animasi Wajah 3D dengan Teknologi Motion Capture. REKAM: Jurnal Fotografi, Televisi, Dan Animasi. https:// doi.org/10.24821/rekam.v14i2.1747

Hasan, R. V., Simatupang, G. R. L. L., \& Saputro, K. A. (2018). Klaim Kebenaran Filmis Dokumenter: Problem dan Alternatif Sudut Pandang. REKAM: Jurnal Fotografi, Televisi, Animasi. https://doi.org/10.24821/ rekam.v14i2.1715

Maulana, A. (2015). Iklan Layanan Masyarakat Pencegahan Penyakit Karies pada Anak. Jurnal E-Proceeding, 2(2), 629.

Santosa, S. (2009). Creative Media. Retrieved from http://ejournal.ilkom.fisip-unmul. ac.id/site/wp-content/uploads/2017/06/Ejournal Syaif (Format Online) (06-13-1708-21-33).pdf

Setiawan, A. B. (2014). Pengaruh Penggunaan Media Animasi Terhadap Hasil Belajar Rencana Anggaran Biaya di SMK Negeri 3 Yogyakarta. Universitas Negeri Yogyakarta.

Sugiyono.(2012). MetodePenelitianKuantitatif, Kualitatif dan R \& D.Bandung: Alfabeta. Metode Penelitian Kuantitatif, Kualitatif Dan $R \&$ D.Bandung:Alfabeta. https://doi. org/10.1017/CBO9781107415324.004

Sukiyasa,K., \& Sukoco, S. (2013).Pengaruhmedia animasi terhadap hasil belajar dan motivasi belajar siswa materi sistem kelistrikan otomotif. Jurnal Pendidikan Vokasi. https:// doi.org/10.21831/jpv.v3i1.1588
Syarif, A. M., \& Al Ahdaf, Y. H. (2017). Iklan Layanan Masyarakat Animasi 2D Pencegahan Pencemaran Air di Kota Semarang. Universitas Dian Nuswantoro. 
